\title{
Familial orofaciodigital syndrome type I presenting as adult polycystic kidney disease
}

\author{
D DONNAI, L KERZIN-STORRAR, AND R HARRIS
}

From the Department of Medical Genetics, St Mary's Hospital, Manchester M13 0JH.

SUMmARY A three generation family with orofaciodigital syndrome type $\mathrm{I}$ is described. Several family members had been thought to suffer from autosomal dominant polycystic kidney diseasec but examination of the proband led to establishment of the correct diagnosis. The genetic $f$ implications for the offspring of the affected women and other family members were significantly ${ }_{\infty}^{N}$ altered.

Orofaciodigital syndrome type I (OFD I) was first described by Papillon-Léage and Psaume ${ }^{1}$ in 1954 and further delineated by Gorlin and Psaume ${ }^{2}$ in 1962. It is a multiple congenital anomaly syndrome consisting of oral frenulae and clefts, hamartomata of the tongue, hypoplasia of the nasal alae, asymmetrical shortening of the digits with occasional preaxial polydactyly of the feet, and retardation in about half of affected subjects. OFD I usually occurs in females and has been reported in several generations, consistent with an $\mathrm{X}$ linked dominant mode of inheritance with lethality in affected males. Doege $e t$ $a l^{3}$ reported polycystic kidneys at necropsy in a mother and daughter with this syndrome but considered it to be a separate genetic entity, and Majewski $e t a l^{4}$ found polycystic anomalies of the kidneys in five of seven necropsied cases with OFD I. Harrod $e t a l^{5}$ reported a patient who presented with polycystic kidney disease and was found to have the

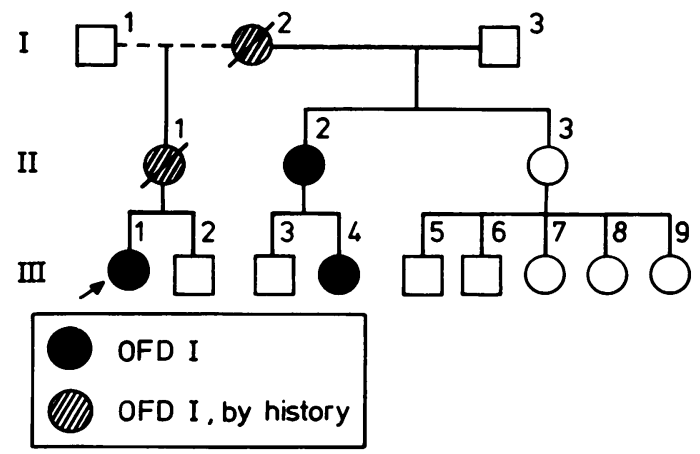

FIG 1 Family pedigree.

Received for publication 7 January 1986 Accepted for publication 13 March 1986 classical features of OFD I but no family history. We report a family referred to the Genetic Clinic with a을 diagnosis of autosomal dominant polycystic kidneyฏ disease (ADPKD). History and examination revealed OFD I in five females in three generations (fig. 1).

\section{Case reports}

III. 1

A 21 year old moderately mentally retarded female was referred for genetic counselling with a diagnosiso

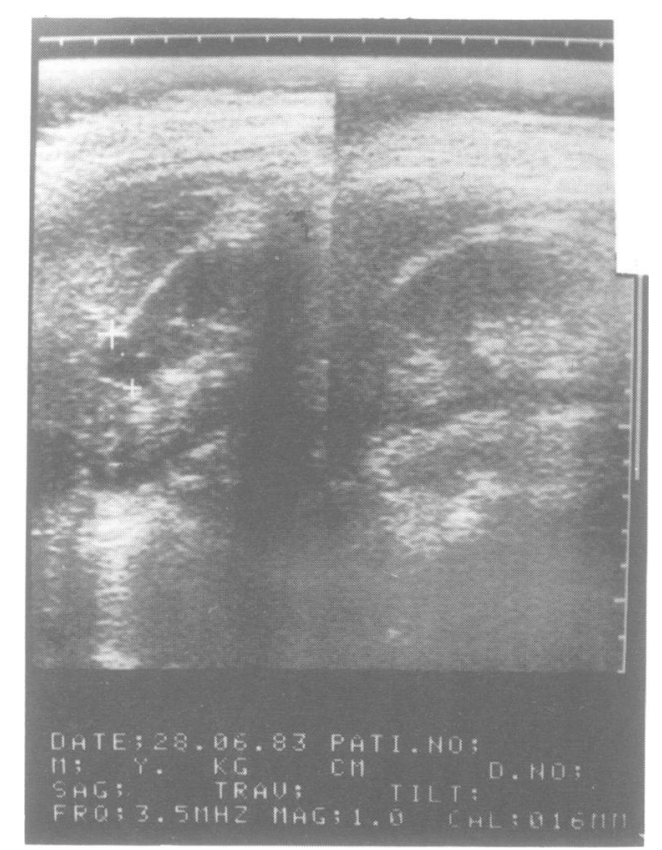

FIG 2 Ultrasound scan of right kidney of III.1 showing cyst on anterior surface. 
of ADPKD. Ultrasound scan of her kidneys performed because of family history revealed a small cyst $11 \mathrm{~mm}$ in diameter on the anterior surface of the right kidney (fig 2) and a $1 \mathrm{~cm}$ cyst on the left. On examination in the Genetic Clinic she was short (height $137 \mathrm{~cm},<3$ rd centile). The occipitofrontal circumference was $61 \mathrm{~cm}(>97$ th centile), there was facial asymmetry, slight downward slant of the palpebral fissures, and deep pitted lesions over both cheeks with a few milia under the right eye (fig 3 ). There was a small cleft of the upper lip to the right of

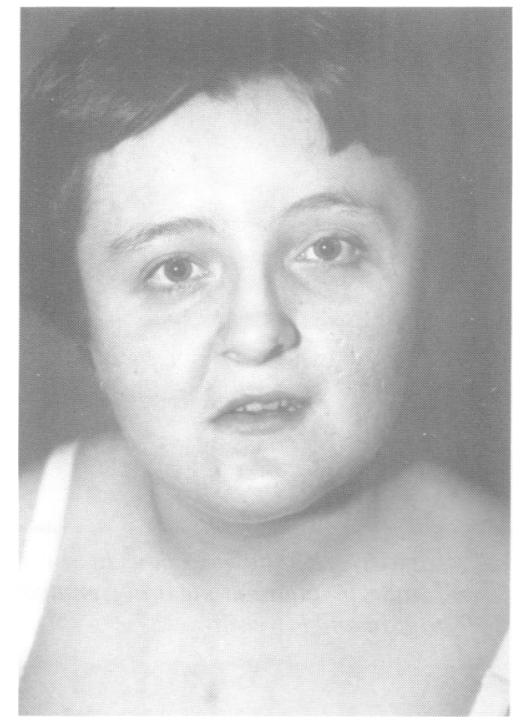

FIG 3 III.1 at 21 years showing facial asymmetry, pitted lesions on cheeks, and small cleft of upper lip to the right of the midline. the midline, multiple oral frenulae, and an irregular tongue border. There was brachydactyly of all fingers, the right fifth digit being extremely short with complete cutaneous syndactyly with the fourth fingers (fig 4). Both halluces were broad and there was a scar on the right where a preaxial digit had been removed. A history was obtained of convulsions from the age of two months, which were localised to the right side of the body. She was delayed in her motor and mental development and had required education in a special school.

III. 4

The 21 year old cousin of the proband had a cleft palate which had been repaired at the age of two years and a hamartomatous lesion had been removed from the tongue at the age of 16 years. She had right conductive deafness for which a hearing aid was required. On examination she was short (height $142 \mathrm{~cm},<3$ rd centile). She had a medial eyebrow flare, downward slanting palpebral fissures, and milia under both the lower eyelids. The lip margin was irregular, multiple oral frenulae were present between the lips and the gums, and there was a cleft in the right upper alveolar margin. The tongue was irregular and showed the scars of previous surgery (fig 5). There was brachydactyly of all fingers with clinodactyly of the fourth and fifth. The feet were short with a $1 \mathrm{~cm}$ difference between the two sides. The patient had a marked tremor accentuated by anxiety and tiredness. Ultrasound scan revealed cysts in one kidney.

II. 2

The 54 year old mother of III. 4 is currently attending hospital for management of declining renal function due to polycystic kidneys. On examination, her

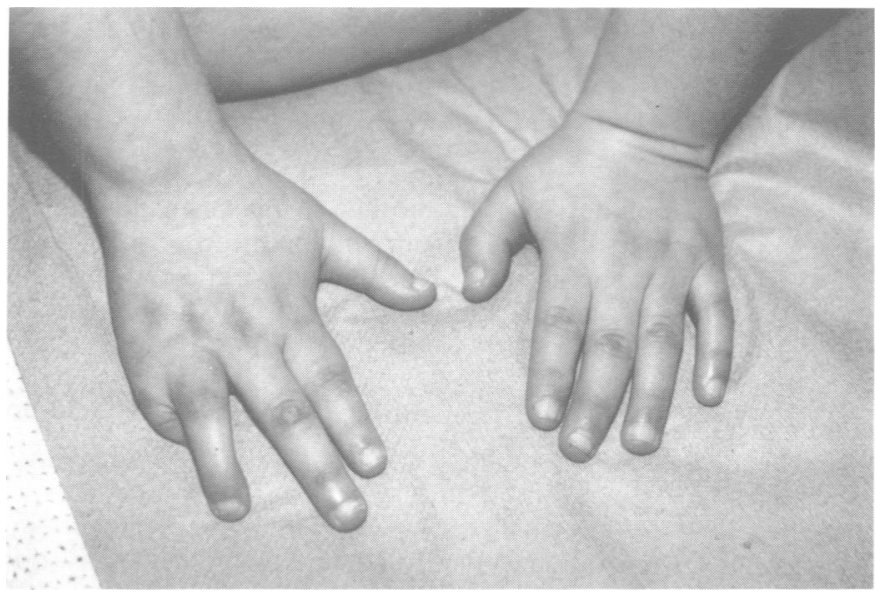

FIG 4 Hands of III.1 showing asymmetrical brachydactyly, very short fifth finger of right hand, and cutaneous syndactyly with fourth finger. 


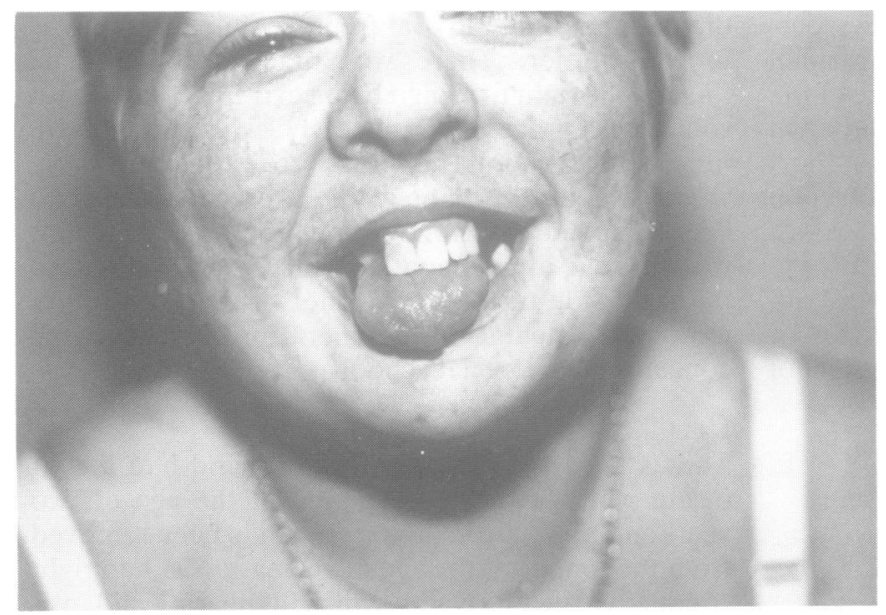

FIG 5 III. 4 at 21 years showing cleft in right upper alveolar margin and irregular tongue margin.

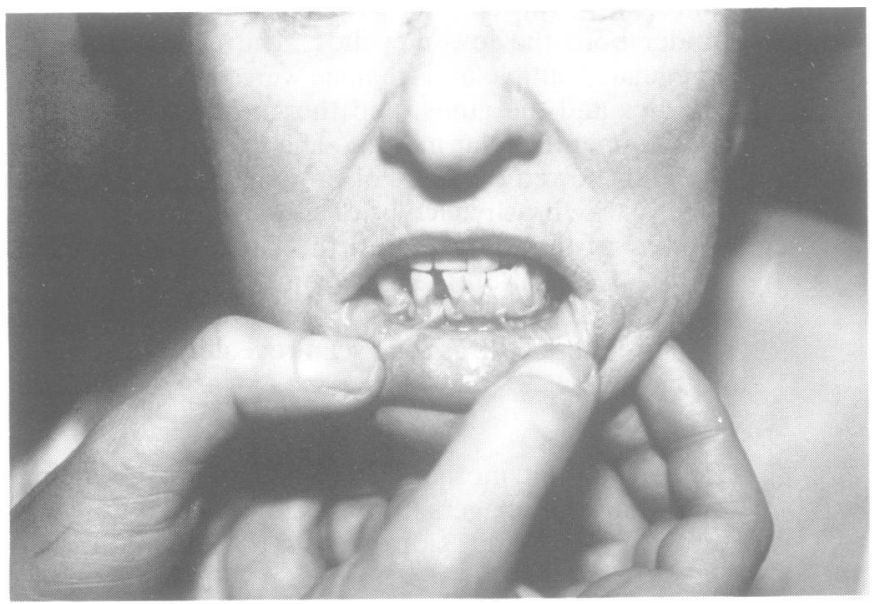

FIG 6 II.2 showing clefts in lower alveolar margin and multiple oral frenulae between gum and lower lip.

height was $157.5 \mathrm{~cm}$ (10th to 25 th centile). The lower lip margin was irregular, there was a deep cleft in the alveolar margin in the bottom jaw on either side of the right lateral incisor, and multiple oral frenulae were present between the bottom lip and the gum margin (fig 6). The tongue had a bifid tip but was otherwise normal. The hands and feet were normal apart from mild brachydactyly.

\section{II . 1}

The mother of III.1 died aged 64 years of uraemia secondary to chronic renal failure due to polycystic kidneys. At the age of 40 years she presented with a 12 month history of loin pain and IVP revealed deformed renal pelves. Laparotomy was performed and showed multiple small cysts of the kidneys. Her half sister (II.2) reported that she was deaf and had 0 very short and 'curved in' fingers.

I . 2

The maternal grandmother of the proband died at $N$ the age of 53 years from renal failure associated with $N$ polycystic kidneys. Her daughter reported that she had very short fingers and skin folds in her mouth which needed to be 'snipped' before dentures could $₹$ be fitted.

III.2, III.3, II.3, and III.7 were examined and no evidence of OFD I found.

\section{Discussion}

Orofaciodigital syndrome type I affects many dif- $\frac{\stackrel{\rho}{\Phi}}{\Phi}$ ferent parts of the body. The externally visible $\frac{0}{0}$ 
anomalies are well described but internal anomalies including those of the kidney are less well documented. Polycystic kidneys have been found in patients with OFD I at necropsy ${ }^{34}$ and as a presenting feature in an apparently sporadic case. ${ }^{5}$ The family reported here further demonstrates that polycystic kidney is a feature of OFD I. The fact that only females were affected in three generations in this family lends support to the hypothesis that OFD I is an $\mathrm{X}$ linked dominant trait with lethality in affected males. ${ }^{3}$

The presence of mental retardation and oral and digital anomalies led to the unifying diagnosis in the proband and hence accurate genetic counselling could be given to family members. This was important both to the unaffected males (and their children) now shown not to be at risk for ADPKD and to the affected females whose daughters have a 1 in 2 risk of inheriting OFD I. We suggest that features of OFD I should be looked for in a family where only females have polycystic kidneys. Conversely, females diagnosed on external features as having OFD I should have renal investigations performed.
We acknowledge the help of Dr E A Watters for visiting members of this family and Ms S Garnett for typing the manuscript.

\section{References}

I Papillon-Léage (Mme), Psaume J. Une malformation hereditaire de la maqueuse buccale: brides et freins anormaux. Rev Stomatol (Paris) 1954;55:209-27.

2 Gorlin RJ. Psaume J. Orodigitofacial dysostosis-a new syndrome. J Pediatr 1962;61:520-30.

${ }^{3}$ Doege TC, Thuline HC, Priest JH, Norby DE, Bryant JS. Studies of a family with the oral-facial digital syndrome. $N$ Engl J Med 1964;271:1073-80.

${ }^{4}$ Majewski F, Lenz W, Pfeiffer RA, Tunte W, Muller H. Das orofacio-digitale Syndrom: Symptome und Prognose. $Z$ Kinderheilkd 1972;112:89-112.

5 Harrod MJE, Stokes J, Peede LF, Goldstein JL. Polycystic kidney disease in a patient with the oral-facial-digital syndrometype I. Clin Genet 1976;9:183-6.

Correspondence and requests for reprints to Dr D Donnai, Department of Medical Genetics, St Mary's Hospital, Hathersage Road, Manchester M13 0JH. 